\title{
Moving From Problem-Oriented to Goal-Directed Health Records
}

\author{
Zsolt J. Nagykaldi, $P b D^{1}$ \\ Huibert Tange, $M D, P b D^{2}$ \\ Jan De Maeseneer, $M D, P b D^{3}$ \\ ${ }^{1}$ Department of Family and Preven- \\ tive Medicine, University of Oklahoma \\ Health Sciences Center, Oklahoma City, \\ Oklahoma \\ ${ }^{2}$ Department of Family Medicine, Maas- \\ tricht University, Maastricht, The \\ Netherlands \\ ${ }^{3}$ Department of Family Medicine and \\ Primary Health Care, Ghent University, \\ Ghent, Belgium
}

\begin{abstract}
Electronic health records (EHRs) have been in place for decades; however, most existing systems were designed in the prevailing disease- and payment-focused care paradigm that often loses sight of the goals, needs, and values of patients and clinicians. The goal-directed health care model was proposed more than 20 years ago, but no design principles have been developed for corresponding electronic record systems. Newly designed EHRs are needed to facilitate health care that is anchored by patient life and health goals. We explore the limitations of current EHRs and propose a blueprint for a new EHR design that may facilitate goal-directed health care. To reflect patient goals as a thread through the care continuum, we propose 5 major system functions for goal-directed health records based on the 8 characteristics of primary health care defined by the Institute of Medicine. We also discuss how new EHR functions could support goal-directed health care and how payment and quality measurement systems will need to be transformed. It may be possible for patient life and health goals to drive health care that is reinforced by a corresponding health record design; however, synchronized shifts must occur in the models of providing, documenting, and paying for health care.
\end{abstract}

Ann Fam Med 2018;16:155-159. https://doi.org/10.1370/afm.2180.

\section{INTRODUCTION}

$\mathrm{H}$

ealth care professionals have used electronic health records (EHRs) for decades to document patients' interactions with the health care system. Initially, primary care clinicians, in particular, were optimistic that computer technology would facilitate higher quality care that was more cost-effective and patient-centered. But there is now ample evidence that the diffusion of EHRs has not resulted in all the desired outcomes clinicians and patients anticipated. A recent paper in The Lancet by Martin and Sinsky describes how clinical documentation (record keeping) was redefined in the 20th century and how control over documentation was gradually taken from health care professionals. ${ }^{1}$ Martin and Sinsky argue that mandates from legislators, health care administrators, and payers to document care delivery now supersede the needs of clinicians to create a record that effectively informs continuous patient care with relevant and actionable information.

Martin and Sinsky make valid and timely points, but there is more to uncover about fundamental problems with the current approach to the design, delivery, and documentation of health care. Several authors have argued that the biomedical model of medicine encourages health professionals to approach patient care in a limited, disease-focused framework..$^{2-4}$ Evidence-based clinical guidelines for individual diseases often collide with the complexity presented by patients suffering from multiple health conditions. This approach ignores the reality that people are complex adaptive systems and fails to acknowledge nonlinear patterns of interaction between the patient and the environment and within the patient. ${ }^{5}$ Additionally, guidelines for single diseases tend to generate a long list of problems in older adults and an even longer list of medical strategies 
and tasks for the patients, caregivers, and clinicians to manage. This is a substantial challenge in primary care, especially with elderly patients. When clinicians are compelled by the health care system to address problems without being able to consider their relative importance or long-term impact on patients' goals, needs, and preferences, health care may not be effective, feasible, or sustainable.

The goal-directed health care model ${ }^{3,6-8}$ proposes an approach that uses patients' life and health goals to guide health care professionals in cocreating personalized care plans that are responsive to the shared priorities, needs, preferences, and values of patients. ${ }^{3}$ The paucity of long-term goal setting in conversations at comprehensive wellness visits ${ }^{9}$ clearly indicates the need for a more patient-centered health care approach

\section{Care Paradigms and the Architecture of Medical Records}

Unfortunately, most EHRs have been designed in a problem-oriented and fee-for-documentation framework, which reinforces a corresponding care approach. Historically, most electronic records in the United States were developed in medical billing organizations that extended their systems to include clinical documentation. It is therefore not surprising that the underlying design of these systems supports the management of medical problems and the tracking of procedures in order to calculate the value of health professionals' work.

The circular relationship between medical record design and care models is evident in the struggle of primary care clinicians to maintain control over the content, delivery, and documentation of patient-centered care. The design of current EHRs may reinforce episodic, procedure-driven care, as opposed to continuous, collaborative, whole-person-centered primary care. For general medicine, a simple transactional EHR design may be inappropriate because overly standardized care is neither feasible nor desirable. Complex primary care requires personalization and prioritization based on the specific needs, goals, and circumstances of individuals. Current medical records are ill-designed to support longitudinal, personalized health care provided by diverse professional teams in multiple settings and times. They offer little help to patients and clinicians to set and track health goals across the care continuum, and make it difficult to prioritize care strategies when an array of competing health needs arise.

\section{THE GOAL-DIRECTED HEALTH RECORD}

A goal-directed health record would not simply reorganize information in the EHR in a new way, but by positioning life and health goals as the starting point it would help refocus medical professionals on the full scope of human health. A core principle of the goal-directed health record is to capture and track the accomplishment of long-term patient goals that are established with the health care team. Since longterm goal setting needs to precede medical testing and therapy, the goal-directed health care model proposes that the process of care is initiated by the assessment of patient aspirations, preferences, and values. Goal orientation is relevant not only to older individuals, but also to young, healthy persons, whose long-term goals often relate to ongoing personal development and maximizing their human potential.

A core function with a detailed personal profile could, therefore, drive a goal-directed health record's data architecture, user interfaces, data capture and storage processes, and other features. The Institute of Medicine (IOM) describes primary care as personcentered, accessible, comprehensive, coordinated, continuous, accountable, integrated, and partnershipbased. ${ }^{10}$ These characteristics have been operationalized by Mold et $\mathrm{al}^{11}$ in a primary care logic model that maps the IOM characteristics of primary care to intermediate and final outcomes. Outcomes include increased life span, improved quality of life, productivity, end-of-life quality, satisfaction with care, health disparities, costs, and health care professional wellbeing. ${ }^{11}$ In 2014, a group of primary care researchers, led by Krist et al, created a consensus statement, based on this model, to bridge technology gaps in current EHRs. ${ }^{12}$ The logic model provides a framework for redesigning health records for primary health care. It focuses on the achievement of important life and health goals and emphasizes the team-based, collaborative, and community-linked nature of primary care. ${ }^{13}$

Effective collaboration is not possible without health records that link health care activities to patient goals and that are shared across care settings. Efficient care coordination requires technical support for information exchange and links to patient goals that form a virtual thread running through care settings, data sources, record systems, medical specialties, payment approaches, and administrative processes. A medical record can be characterized as goal-directed when health professionals using them are reminded to consider asking the patient questions similar to the following: (1) What do we need to achieve today? and (2) Are the objectives that we need to meet today aligned with your long-term goals? Questions such as these may be valid, even in acute care situations, because short-term therapies may have an effect on the patient's continuing management or result in potential adverse outcomes through an unintended medical cascade effect. ${ }^{14}$ 
Although not every care situation requires the clarification of patient goals (for example, a broken arm or a simple upper respiratory infection), in multiple cycles of continuous care, patient harm may be prevented and unnecessary health care expenditures can be averted with an approach that is goal-directed.

Eliciting and leveraging patient goals in health care requires a thoughtful and systematic process. Most health care records, however, contain minimal patient voice. In the current record, patients say little about themselves, their health and life challenges, and what has worked for them in the past. Health care organizations and funders are calling for more access to patientreported outcomes, as they realize that certain types of critical information is most reliably or exclusively obtained from patients. ${ }^{15}$ Yet, few technologies exist that collect and integrate the voice of the patient into the medical record.

Nagykaldi et al developed and tested an advanced and comprehensive health planner that empowers patients to report information for 13 health domains in a goal-directed framework and to receive feedback that may assist them in shared decision-making through a linked patient portal. ${ }^{16}$ Feedback to patients includes tailored life and health expectancy estimates, global wellness scores, actionable health strengths and challenges, and personalized lists of care options that are ranked by their effectiveness in achieving goals. There is a dearth of technologies that integrate comprehensive, patient-reported information and provide feedback linked to patient goal attainment. Turning goals into palatable objectives, setting priorities, and creating action steps (care plans), requires the right information, sophisticated decision support, and health care resources. A medical record system that is able to draw on patient information and link decisions to health goals using a shared decision-making process may be able to facilitate this process.

More research is needed to determine how patients and health care professionals can most effectively collaborate using goal-directed health records. In recent implementation studies, patients could document and periodically update their long-term goals, which were then presented to clinicians during annual wellness visits to help them negotiate health care objectives and specific care strategies. ${ }^{9,16,17}$

Finally, the goal-directed health record needs to consider the person's life and health context, which may interact with the patient's health in a complex manner (eg, family/community support, access to care, lack of transportation). Current health records, however, are not adequate for helping clinicians evaluate interactions between the patient's health conditions and their environment. For example, in a goal-directed record, users would need to be able to plot blood pressure readings over information layers that might include medication logs, symptoms, life events, or laboratory test results. These interactive analytical features could be extremely helpful for tailoring therapies that are aligned with patient goals. Similarly, automated and smart monitoring and presentation of trends, linked to outlier detection and alerts will be needed to support goal setting and goal attainment at both the patient and community level. These features can also support the integration of primary care and population health. Community-engaged primary care is an excellent approach to formulating community diagnoses, giving feedback to the health and social systems, and informing population-level interventions based on higher-level goals. ${ }^{18}$

To create goal-directed electronic health records, the authors suggest the following major functions to be incorporated into existing EHRs: patient profile (core), health planner, health care tracking, health care collaboration and context, and community health integration. Table 1 provides detailed information about each of these functions.

\section{A STARTING POINT}

Even if medical records cannot be fundamentally redesigned at this point, inclusion of the core patient profile and health planner functions and creation of linkages between patient characteristics and other parts of the EHR could help us move toward a goaldirected health record. As a first step, patient attributes captured by EHRs need to expand to include actionable sociocultural and socioeconomic information, life and health goals, care preferences, and personal risk factors. These patient attributes would need to be captured as structured data, because free-text notes are difficult to operationalize. Once the attributes are captured as structured data, they can be leveraged by other EHR components to help patients and clinicians coconstruct personalized care. To accomplish this, a new taxonomy for personal health attributes needs to be developed that incorporates categories of patient goals (eg, those related to life extension, health-related quality of life, physical functioning, human development, end of life, and health care relationships). These attributes will then need to be linked to evidencebased strategies that can promote the achievement of patient goals. For example, when patients indicate that physical activity is highly important to them, that preference should inform medication and therapy choices through built-in clinical decision-support by prioritizing options that preserve physical functioning and by triggering a review of options that may inter- 
fere with physical activity. Similarly, health care could be more effectively personalized if patient goals for cognitive functioning could directly inform selections made in the prescribing, physician order entry, and care planning modules of the electronic health record. In a goal-directed record, instead of being treatment targets, individual health conditions and diagnoses would act as risk factors for adverse outcomes that might impede goal attainment. A diagnosis of type 2 diabetes could trigger a list of major risk factors (eg, cardiovascular, respiratory, neurologic, etc) that have specific and known effects on longevity and quality of life (eg, myocardial infarction, stroke, diminishing ambulatory or visual abilities, lifestyle restrictions, etc) each affecting the person differently depending on

Table 1. Functions to Incorporate into a Goal-Directed EHR

\begin{tabular}{|c|c|}
\hline Function & Description \\
\hline Patient profile (core) & $\begin{array}{l}\text { Longitudinal patient profile and health history in the patient's } \\
\text { voice with health goals and levels of attainment (including } \\
\text { barriers and facilitators) linked to each functional domain of } \\
\text { the EHR to support shared decision-making. }\end{array}$ \\
\hline \multicolumn{2}{|l|}{ Health planning } \\
\hline Longevity & $\begin{array}{l}\text { Patient and professional health assessment updated periodically } \\
\text { to produce global health metrics (life and health expectancy, } \\
\text { "body age," wellness score, qualitative health strengths and } \\
\text { challenges, total health benefit if all goals are achieved, and } \\
\text { specific health benefits for individual care strategies). }\end{array}$ \\
\hline $\begin{array}{l}\text { Health-related quality } \\
\text { of life }\end{array}$ & $\begin{array}{l}\text { Assessment and tracking of health-related quality of life (mean- } \\
\text { ingful life activities current level of functioning, eg, ICF,20 } \\
\text { quality of life goals, readiness to address quality goals, and } \\
\text { goal attainment scaling. }\end{array}$ \\
\hline Personal development & $\begin{array}{l}\text { Assessment and tracking of development connected with achiev- } \\
\text { ing life and health goals. These may include developmental } \\
\text { milestones (Erikson), psychological needs (Deci and Ryan), } \\
\text { adult learning (Zubialde, Mold, and Eubank), physiologic resil- } \\
\text { ience, and spiritual development. }\end{array}$ \\
\hline $\begin{array}{l}\text { Family and social } \\
\text { context }\end{array}$ & $\begin{array}{l}\text { Review of the patient's family and social environment related } \\
\text { to health care support and the impact of sociocultural, eco- } \\
\text { nomic, and personal value factors on the individual's health } \\
\text { care (eg, by using genograms). }\end{array}$ \\
\hline Advance care planning & $\begin{array}{l}\text { Completion and tracking of advance directives (care plans) and } \\
\text { end-of-life care choices. }\end{array}$ \\
\hline \multicolumn{2}{|l|}{ Health care tracking } \\
\hline Care narrative & $\begin{array}{l}\text { Description of the patient's health status and encounters with } \\
\text { the health care system that can be searched using natural } \\
\text { language processing and linked to recommendations using } \\
\text { advanced primary care terminology. }{ }^{21}\end{array}$ \\
\hline Quantitative data & $\begin{array}{l}\text { Test results, imaging, reports, integrated person and popula- } \\
\text { tion-level preventive services registry, and forecasting system } \\
\text { linked to EHR } 2.0 \text { functionality to trend multiple, linked layers } \\
\text { of data including life and health events. }\end{array}$ \\
\hline \multicolumn{2}{|l|}{$\begin{array}{l}\text { Health care collabora- } \\
\text { tion and context }\end{array}$} \\
\hline $\begin{array}{l}\text { Interdisciplinary } \\
\text { communication }\end{array}$ & $\begin{array}{l}\text { Advanced interdisciplinary and interorganization communica- } \\
\text { tion, including transmission of core patient profile information } \\
\text { using multiple layers (clinical and administrative information). }\end{array}$ \\
\hline $\begin{array}{l}\text { Health data } \\
\text { interoperability }\end{array}$ & $\begin{array}{l}\text { Connections to regional systems or information exchanges (com- } \\
\text { munity record sources) with the option of 1-click discrete data } \\
\text { element transfer into the local record, if needed. }\end{array}$ \\
\hline $\begin{array}{l}\text { Community and } \\
\text { population health } \\
\text { integration }\end{array}$ & $\begin{array}{l}\text { Continuous and automated data mining system and signal detec- } \\
\text { tion responsive to individual and population health goals, } \\
\text { linked to point-of-care and prospective decision support. }\end{array}$ \\
\hline
\end{tabular}

EHR = Electronic Health Record; ICF = International Classification of Functioning, Disability and Health. their goals. Thus, goal-directed health records could help health care professionals focus on the patient and use the granular knowledge accumulated in the EHR to tailor medical strategies that may improve the patient's health trajectory.

\section{THE ELEPHANT IN THE ROOM: CURRENT APPROACHES FOR MEASURING AND PAYING FOR HEALTH CARE}

When health care innovations are proposed, we frequently hear the following questions: "Who will pay for it?" or "Is it possible, if the payment system remains unchanged?" The implementation of goal-directed medical records may involve not only technology innovations, but also new payment models that are better aligned with the need to measure and pay for outcomes that matter to patients and clinicians. Current payment models assume that the value of health care can be determined across wide groups of patients and providers in a relatively uniform manner. In goal-directed health care, however, the value and the measure of quality are not the same for each individual. This means that health care quality is defined as the level of attainment of shared (patient/clinician) goals described by the person's individualized health care plan. Goal attainment can be measured in a variety of ways, including goal-specific scales and global health scores that change according to the individual's health trajectory. Traditional quality metrics (process metrics used in pay-for-performance programs) are not preferred because they are not able to capture individual needs and goals for health care. In a goal-directed framework, payers and administrators may not be able to apply simple and uniform measures across the board to assess the quality or value of care. This may necessitate the rethinking of coding systems and metrics that are currently used to measure the quality of primary health care in order to reflect its most enduring qualities, such as, continuity, patientcenteredness, coordination, and 
sensitivity to context. Coding systems, including the International Classification of Primary Care 2 (ICPC2) $)^{19}$ and the International Classification of Functioning, Disability and Health (ICF ${ }^{20}$ are already available and provide frameworks that are more aligned with goaldirected health care. A focus on patient goal attainment, patient health potential, individual health, and population health, as opposed to medical interventions aimed at correcting abnormalities, will require substantial change in the conceptual and practical approach at all levels of health care. Goal-directed health records could more effectively drive the provision and documentation of health care compared with process outcomes and administrative objectives, which currently drive the health care system.

\section{CONCLUSIONS}

Numerous systemic and administrative health care innovations have been tried, but the overarching problem-oriented approach to care and its conceptual image coded into the medical record remain the same across innovations. It may be possible for patient life and health goals to drive health care that is reinforced by a corresponding medical record design; however, synchronized shifts will need to occur in the domains of providing, documenting, and paying for care. In addition to past attempts to reform health care that were focused on access, delivery, and payment, our current electronic medical records will also need to be redesigned to incorporate the functions outlined in this paper, if we are to achieve the quadruple aim ${ }^{21}$ and the aspirations of primary care clinicians and patients. Additional research is needed to establish best practices for how patients and health care teams can partner more effectively through goal-directed health records. As these records are developed and tested, their impact on individual and population health and the cost of health care will also need to be established through ongoing research.

To read or post commentaries in response to this article, see it online at http://www.AnnFamMed.org/content/16/2/155.

Key words: problem-oriented; goal-directed; medical record; documentation; primary care

Submitted December 29, 2016; submitted, revised, July 24, 2017; accepted August 7, 2017.

Acknowledgments: The authors would like to thank Dr James Mold, Professor Emeritus, for his support and excellent comments that helped improve this manuscript.

\section{References}

1. Martin SA, Sinsky CA. The map is not the territory: medical records and 21st century practice. Lancet. 2016;388(10055):2053-2056.

2. Blossom HJ. Goal-oriented care. Fam Med. 1991;23(4):248.

3. Mold JW, Blake GH, Becker LA. Goal-oriented medical care. Fam Med. 1991;23(1):46-51.

4. De Maeseneer J, Boeckxstaens P. James Mackenzie Lecture 2011: multimorbidity, goal-oriented care, and equity. Br J Gen Pract. 2012; 62(600):e522-e524.

5. Sturmberg JP, Bennett JM, Martin CM, Picard M. 'Multimorbidity' as the manifestation of network disturbances. J Eval Clin Pract. 2017; 23(1):199-208.

6. Mold J. Goal-directed health care: redefining health and health care in the era of value-based care. Cureus. 2017;9(2):e1043.

7. Mold JW, Nagykaldi Z, Purkaple B. The goal-directed health care model. https://www.goaldirectedhealthcare.org/. Published Jan 2017. Accessed Jun 5, 2017.

8. Mold JW, Hamm R, Scheid D. Evidence-based medicine meets goal-directed health care. Fam Med. 2003;35(5):360-364.

9. Nagykaldi Z, Dave A, Kristof C, Watts T, Utpala S, Wickersham E. Improving patient-clinician conversations during annual wellness visits. J Am Board Fam Med. 2017;30(2):161-169.

10. Donaldson MS, Yordy KD, Lohr KN, et al. Primary care: America's health in a new era. Washington, DC: The National Academies Press; 1996.

11. Mold JW, Lienke RI, Drew B. How primary care produces better outcomes: a logic model. North American Primary Care Research Group (NAPCRG). http://www.napcrg.org/Resources. Published 2014. Accessed Feb 2, 2018.

12. Krist AH, Beasley JW, Crosson JC, et al. Electronic health record functionality needed to better support primary care. J Am Med Inform Assoc. 2014;21(5):764-771.

13. Rhyne R, Cashman S, Kantrowitz M. An introduction to communityoriented primary care. In: Rhyne R, ed. Community-Oriented Primary Care: Health Care for the 21st Century. Washington, DC: American Public Health Association; 1998.

14. Mold JW, Stein HF. The cascade effect in the clinical care of patients. N Engl J Med. 1986;314(8):512-514.

15. Deshpande PR, Rajan S, Sudeepthi BL, Abdul Nazir CP. Patientreported outcomes: A new era in clinical research. Perspect Clin Res. 2011;2(4):137-144.

16. Nagykaldi ZJ, Voncken-Brewster V, Aspy CB, Mold JW. Novel computerized health risk appraisal may improve longitudinal health and wellness in primary care: a pilot study. Appl Clin Inform. 2013;4(1): 75-87.

17. Nagykaldi ZJ, Jordan M, Quitoriano J, Ciro CA, Mold JW. Usercentered design and usability testing of an innovative health-related quality of life module. Appl Clin Inform. 2014;5(4):958-970.

18. Rhyne R, ed. Community-Oriented Primary Care: Health Care for the 21st Century: Washington, DC: Amer Public Health Association; 1998.

19. World Health Organization. International classification of primary care, second edition (ICPC-2). World Health Organization Website. http://www.who.int/classifications/icd/adaptations/icpc2/en/. Updated March 2003. Accessed Nov 29, 2016.

20. World Health Organization. International classification of functioning, disability and health (ICF). World Health Organization Website. http://www.who.int/classifications/icf/en/. Accessed Jul 22, 2016.

21. Bodenheimer T, Sinsky C. From triple to quadruple aim: care of the patient requires care of the provider. Ann Fam Med. 2014;12(6): 573-576. 